\title{
Internacionalização de Empresas Russas no Brasil: configurações de transação para o fornecimento de carne bovina
}

\author{
Karim Marini Thomé ${ }^{1}$ \\ Fabrício Oliveira Leitão ${ }^{2}$ \\ José Márcio Carvalho \\ Enzo Lenine Nunes Batista Lima \\ Patrícia Santana Costa Gomes ${ }^{5}$ \\ Marcus Alexandre Rodrigues Ruzzon ${ }^{6}$
}

\section{Resumo}

O presente artigo é um estudo exploratório, em que as variáveis estudadas têm natureza qualitativa. O objetivo é caracterizar como firmas russas atuantes no comércio de carne bovina internacionalizaram seus negócios em direção ao mercado produtor brasileiro. Com a aplicação de 14 entrevistas, chegou-se à construção de quatro configurações de transações que são realizadas por organizações russas no mercado brasileiro. A primeira configuração discutida é a que apresenta o maior número de organizações envolvidas, tem a vantagem de permitir alta especialização das mesmas e de possibilitar as transações com empresas atacadistas e varejistas russas por meio da internacionalização de terceiros (trading companies) em negócios internacionais. Na segunda configuração, observa-se uma maior responsabilidade por parte da empresa atacadista russa, o que se deve ao fato de que esta categoria de organização conseguiu internalizar operações inicialmente atribuídas à trading company. A terceira configuração observada é uma situação transi-

\footnotetext{
${ }^{1}$ Doutorando em administração pela UFLA, consultor ThunderTrade. Endereço: Universidade de Brasília Campus Darcy Ribeiro CaixaPostal 4341, Asa Norte, CEP 70904-970, Brasília-DF - Brasil.E-mail: thome.karim@gmail.com.

${ }^{2}$ Mestre em agronegócio pela UnB, professor no INESC. Endereço: Universidade de Brasília Campus Darcy Ribeiro Caixa-Postal 4341, Asa Norte CEP 70904-970, Brasília - DF - Brasil. E-mail:fabriciofol@hotmail.com.

${ }^{3}$ Doutor em Administração pela Universidade de Reading - UK, professor adjunto na UnB. Endereço: Universidade de Brasília Campus Darcy Ribeiro Caixa-Postal 4341, Asa Norte, CEP 70904-970, Brasília-DF - Brasil.E-mail: jmcarvalho@unb.br.

${ }^{4}$ Bacharel em Relações Internacionais pela UnB, analista de negócios internacionais ThunderTrade. Endereço: Universidade de Brasília Campus Darcy Ribeiro Caixa-Postal 4341, Asa Norte CEP 70904-970, Brasília -DF - Brasil. E-mail: leninelima@gmail.com.

${ }^{5}$ Bacharel em Relações Internacionais pela UNICEUB, consultora de negócios internacionais ThunderTrade. Endereço: SQS 105 bloco I, ap. 504, CEP 70344090, Brasília - DF - Brasil.E-mail: patochan86@gmail.com.

${ }^{6}$ Economista pela UNEB, analista de negócios internacionais ThunderTrade. Endereço: SHCGN 714, Bloco O, Ap. 504 - CEP 70760 775, Brasília-DF-Brasil.E-mail: mruzzon@gmail.com.

Artigo recebido em: 15/07/2009. Aceito em: 27/10/2009. Membro do Corpo Editorial Científico responsável pelo processo editorial: Martinho Isnard Ribeiro de Almeida.
} 
tória em que a trading company com habilitação para varejo russo toma a frente e é o elo entre a organização de varejo russo e a empresa frigorífica exportadora brasileira. A quarta configuração de transação mostrou-se muito eficiente, vez que permite uma grande integração de atividades, eliminando assim intermediários.

Palauras-chave: Internacionalização. Custos de Transação. Comércio Internacional de Carne Bovina. Mercado Russo. Representação gráfica.

\section{Introdução}

Dentre os países de maior expressão na produção de carne bovina estão Estados Unidos da América (EUA), Brasil, União Europeia (UE) e China, que juntos corresponderam a 67\% da oferta de carne bovina no ano de 2006. Quando se analisa em uma perspectiva global, percebe-se que de 2001 a 2005 a produção de carne bovina cresceu 4,7\%. Nota-se, entretanto que neste período a produção brasileira aumentou $21,2 \%$ e a chinesa $30,8 \%$. Por motivos de problemas sanitários de momentos anteriores, EUA e União Europeia tiveram uma redução de produção de 5,5\% e 3,2\%, porém, mesmo com tal redução, esses centros de produção permanecem entre os grandes produtores mundiais de carne bovina (SABADIN, 2006).

Estimativas da FAO (2008) colocam o mercado mundial de carne bovina desossada e industrializada como responsável pela circulação de aproximadamente 40 bilhões de dólares no ano de 2007. Esse mercado vem crescendo mais rapidamente do que o aumento populacional, ou seja, essa informação dá conotação de que o consumo de carne bovina não cresce apenas em função do aumento populacional, mas também devido à mudança de hábitos. Pode-se afirmar que no mundo aumenta o consumo per capita de carne bovina.

O Brasil firmou-se neste cenário, em 2006, como maior exportador mundial de carne bovina, sendo o responsável pelo envio ao mercado externo de 2.420 mil toneladas em 2007. Esse valor representa assim mais de $50 \%$ do volume mundial, resultando em 4.552 milhões de dólares que trouxeram resultados expressivos à balança comercial do país. Apenas para ilustrar a evolução, no período de 2000 a 2007, o Brasil teve um crescimento de $579 \%$ nas exportações desse produto (CNPC, 2008). 
O principal parceiro comercial do Brasil neste setor é a Rússia, que importou o montante de 967 milhões de dólares no ano de 2007 (MAPA, 2008). Inseridas nesse macroambiente contemporâneo estão as empresas, as quais tiveram que agilmente se adaptar a essa nova situação de parcerias e comércio internacional. Freitas (2006) frisa em seu trabalho que a internacionalização de empresas não é mais apenas transpor fronteiras, ressalta que o conceito abrange o foco de aprendizagem, aporte econômico, processos de evolução e preparo de novos ambientes e melhoria do relacionamento organizacional (network).

Diante dessa situação, faz-se necessário um modo diferente de pensar, entender e interpretar estímulos presentes em tal cenário. Organizações russas atuantes no comércio de carne bovina brasileira são o objeto do presente estudo, que visa configurar e analisar a maneira que elas se internacionalizaram no sentido do mercado fornecedor brasileiro. As configurações das transações internacionais são visualizadas por meio da metodologia de Representação Gráfica e interpretadas pelo aporte da Economia dos Custos de Transação.

\section{Referencial Teórico}

\subsection{Internacionalização}

A globalização, intensificada no pós-guerra, teve um suporte institucional na Conferência de Bretton Woods. O mapa econômico mundial sofreu alterações $e$ as fronteiras perderam muito de seu poder. Indubitavelmente, a tecnologia acelerou o processo de internacionalização, quer seja pela volatilização do capital, quer pela simplificação da troca de informações. Nunca se teve um patamar tão grande de interligação, chegando-se a ter uma situação de aldeia global ou globalização (WOODS, 2001).

As organizações inseridas nesse novo sistema macroambiental tiveram que se adaptar à nova situação, que impunha novas diretrizes e competências para o alinhamento de organizações no ato de transpor fronteiras (ANDERSSON, 2004). Assim, admite-se um vasto leque de possibilidade de estudos, tendo como objetivo a internacionalização. No presente estudo foi adotada como referencial teórico a economia organizacional.

Inicialmente deve-se focar a dimensão da firma, das suas atividades, abrangência, características e estrutura para somente então dimensionar a 
capacidade da firma em se moldar ao ambiente exterior, conforme postulado por Mulvihill (1973). A organização que pretende conquistar avanços na internacionalização inicia um processo de aprendizagem no qual novas competências são construídas a partir de competências anteriores.

Freitas (2006) deixa claro que essas atitudes influenciam a decisão do modo de entrada em um negócio internacional e na escolha do local desse negócio. Outro fator a ser pensado é se essa atuação em negócios internacionais trará o resultado esperado pela firma, e se será compensatório levando-se em consideração as mudanças organizacionais necessárias para tal.

Para a iniciação desse processo, no caso a entrada em novos mercados, diversas estratégias podem ser adotadas de acordo com Almeida (2006): a) via agentes importadores ou empresas comerciais exportadoras; b) por meio de rede já estabelecida de outro exportador ou importador; c) via fornecimento de matéria-prima ou produtos semiacabados; d) estabelecimento de joint venture; e) criação de consórcio e cooperativas de importação ou exportação.

Nessa contextualização, é importante discutir o limite organizacional e a sua articulação para a gestão de negócios internacionais. Para tanto, tomase neste artigo o conceito de internacionalização de Ghanatabadi (2005, p. 5) como sendo: "um processo específico de atitudes ou orientações que são associadas aos sucessivos estágios de evolução das operações internacionais".

\subsection{Economia dos Custos de Transação (ECT)}

A ECT foi construída por um grande número de pesquisadores com formações e objetivos variados. Alguns desses investigadores contribuíram para o enriquecimento da teoria com a criação e o uso de novas construções capazes de analisar a complexidade das transações econômicas. Coase (1978) conseguiu o mérito no desenvolvimento da teoria por causa de sua proposta adiantada para visualizar mercados e empresas como estruturas alternativas de governança. No mesmo trabalho, houve a indicação da existência de custos envolvidos nas transações no mercado. Os custos da transação de mercado mais comuns são: o custo de encontrar os preços relevantes; os custos de escrever contratos da transação; e os custos de alcançar o acordo. Se a soma de todos esses custos for elevada, a alternativa será manter a transação dentro de uma única organização. Nesse caso todos os problemas do sistema do preço são substituídos pelo mecanismo da coordenação de uma empresa. 
Inversamente, se o mecanismo da coordenação for demasiado caro, as transações serão executadas em um custo mais baixo fora da estrutura de uma organização, no que se denomina de transações do tipo mercado (COASE, 1978; NORTH, 1990; DOUMA; SCHREUDER, 1998).

Para apreciar as transações, Williamson (1985) propõe a sua análise com base na especificidade dos ativos envolvidos, na frequência com que ocorrem as transações e na incerteza delas. Com base nesses atributos, o autor direciona o pensamento para o limite organizacional exemplificado em uma tipologia de contrato que mostra como a organização desempenha suas atividades, sendo expressas em quatro tipos de contrato: a) clássico; b) neoclássico, c) relacional e d) hierárquico.

A configuração do arranjo contratual desenvolvidos pelas organizações é, basicamente, influenciado pela especificidade dos ativos necessários e com a frequência de ocorrência das transações. O contrato do tipo clássico é empregado principalmente para viabilizar transações que não precisam de ativos específicos e de baixa frequência de ocorrência, no outro extremo, com maior nível de especificidade e frequência, podem culminar na hierarquização de atividades por uma das organizações. As organizações sempre buscam os menores custos de transação (WILLIAMSON, 1993).

\subsection{Comércio Internacional de Carne Bovina}

Para Bliska e Gonçalves (1998, p. 164), o comércio de carne bovina é definido como:

[...] um conjunto de componentes interativos, tais como diferentes sistemas produtivos, fornecedores de serviços e insumos, indústrias de processamento e transformação, distribuição e comercialização de produtos e subprodutos, e seus respectivos consumidores finais.

Tratando-se do comércio internacional, essa conjuntura é muito mais complexa, uma vez que além dos agentes envolvidos, trata-se de interações entre organizações em diferentes ambientes institucionais. No comércio internacional de carne bovina, o maior importador é a Rússia, sendo o seu principal fornecedor o Brasil. Esse comércio movimentou um montante de aproximadamente 1 bilhão de dólares no ano de 2007 (MAPA, 2008). 
A intenção deste artigo é justamente representar e analisar as transações arquitetadas pelas empresas russas atuantes no comércio de carne bovina que internacionalizaram suas operações em direção ao mercado produtor brasileiro. São caracterizadas as possíveis combinações entre os diferentes atores envolvidos neste eixo de comercialização, bem como suas atividades técnicas correspondentes e as principais características das transações comerciais desempenhadas em cada configuração.

Van Duren et al. (1991) demonstram em seu texto que o estudo do comércio deve ser elevado a uma dimensão de disciplina científica, caracterizada por um enfoque sistêmico e multidisciplinar, desenvolvendo um framework (estrutura) que possibilite a descrição das partes relacionadas do comércio como um objeto empírico. Segundo os autores, uma perspectiva denominada de "configuração" seria adequada e necessária à observação desse fenômeno.

Desse modo, fica evidente que ao longo da rota de comercialização, há transações relacionadas a diferentes atores cujo ponto de ligações entre eles é um determinado produto, denominando-se essa disposição de arranjos de transação. Segundo Coase (1937) e Williamson (1975), essas organizações, que negociam um dado produto ou um grupo de produtos, podem usar arranjos diferentes de transação para realizar seu comércio. Isso pode ser entendido como um acordo informal em que a responsabilidade de cada um dos "sócios comerciais" é definida claramente de acordo com a sequência da produção e comércio. Assim, o arranjo de transação está relacionado à maneira pela qual as organizações comerciais interagem para superar dificuldades de mercado e problemas internos.

Os atores envolvidos nas transações internacionais do mercado Russo em questão foram identificados por Thomé et al. (2009) como sendo seis, que podem ser descritos como:

a) Empresa frigorífica exportadora: tem por objetivo adquirir matériaprima com padrão compatível com as exigências, processá-la em carne bovina e comercializá-la. Essa empresa negocia com todos os cinco demais atores listados a seguir e mantém uma alta especificidade de ativos para atender normas de produção internacional.

b) Broker: é o que mantém o menor volume de capital imobilizado em ativos específicos dentre as organizações mencionadas. Suas 
atividades giram em torno de sua rede de relacionamentos, sendo um ator comissionado e usualmente acionado pelos outros atores, a fim de fazer ligações entre eles, podendo ser utilizado principalmente na entrada de novas regiões. Suas contrapartes são o ator frigorífico exportador tocantinense, os atores de distribuição e os varejistas russos.

c) Trading company com habilitação para atacado: é uma empresa que se dedica a operações de compra e venda em cenário internacional ligando, assim, no caso de carne, empresas frigoríficas exportadoras com empresas distribuidoras no mercado russo.

d) Trading company com habilitação para varejo: também é um ator que se dedica a operações de compra e venda em cenário internacional. Contudo, essa categoria de organização, diferentemente da anterior, pode efetuar transações diretas com empresas varejistas russas. Isso se deve a um alvará específico pois, neste caso, as especificidades dos ativos também são maiores.

e) Empresa distribuidora russa: detém uma rede de informações muito atualizada. Essa empresa negocia com empresas frigoríficas, trading companies, brokers e empresas varejistas. Sua base de negociação é fixada inicialmente na especificação do ativo transacionado, na sequência, no valor e na data de embarque dele.

f) Empresa varejista russa: esse grupo de organizações é composto de redes varejistas, açougues e boutiques de carne. Mantém contrapartes negociáveis com todos os atores já mencionados, exceto a trading company com habilitação para o atacado russo. Essa empresa tem uma alta especificidade dos ativos empregados, sobretudo na disposição do produto e quanto à mão de obra especializada no setor.

A diferença entre trading company com habilitação para atacado e varejo russo fica visível no tocante à especificidade dos ativos envolvidos e por parte da concessão de habilitação de comercialização cedida pelo ambiente institucional russo, o qual apresenta diretrizes muito peculiares para a permissão ou não da habilitação. 


\section{Método e Procedimentos de Pesquisa}

De acordo com o propósito do presente trabalho, pode-se considerá-lo exploratório, vez que, segundo Tripodi, Fellin e Meyer (1975, p. 65),

[...] estudos exploratórios são investigações de pesquisa empírica que têm como finalidade a formação de um problema ou questões, desenvolvendo hipótese ou aumentando a familiaridade de um investigado com o fenômeno ou ambiente para uma pesquisa futura mais precisa.

De acordo com esses autores, para uma pesquisa ser considerada exploratória, ela deve preencher três requisitos, que aqui são contemplados.

Destarte, o presente trabalho classifica-se como estudo de caso e, quanto à natureza das variáveis, classifica-se em qualitativa, já que a pesquisa qualitativa tem o ambiente natural como fonte direta de dados e o pesquisador como instrumento essencial. Foi mantido contato direto e prolongado do pesquisador com o ambiente e com a situação que está sendo estudada. Este estudo não procura enumerar ou medir os eventos estudados, nem emprega instrumental estatístico na análise dos dados, porém busca compreender o fenômeno de maneira contextualizada, por meio de uma análise em perspectiva integrada (GODOY, 1995).

Para coletar os dados primários, lançou-se mão de um roteiro de entrevistas semiestruturadas realizadas durante os dias $1^{\circ}$ a 12 de dezembro de 2008. Tais entrevistas foram conduzidas segundo as indicações de Flick (2004), direcionadas de modo que o entrevistador construísse as configurações de transações presentes na comercialização de carne bovina brasileira para o mercado russo. As entrevistas sempre se deram de maneira formal, seguindo um roteiro simples de apresentação do pesquisador e dos objetivos da pesquisa. Na segunda etapa, tinha-se o questionamento das atividades desempenhadas (atividades técnicas) para cada ator existente. Já na terceira etapa, indagou-se como era conduzida a comercialização e os aspectos de negociação envolvidos com o produto em questão e com os tipos de transações existentes, incluindo as contrapartes e os atributos relacionados a elas. Foram realizadas em inglês e por telefone, além de serem gravadas para posteriores consultas. 
As entrevistas não foram estratificadas em nenhum parâmetro de volume comercializado, ou atividade desempenhada: foram centradas em agentes pré-estabelecidos encontrados na literatura, sendo três empresas varejistas russas (uma era multinacional), três empresas distribuidoras russas, dois brokers, cinco trading companies (duas com habilitação para atacado russo e três com habilitação para atacado e varejo russo) e uma empresa frigorífica tocantinense exportadora. Uma das pesquisas é de caráter não-probabilístico e foi realizada através de uma amostragem por conveniência (MATTAR, 1996), desenhando assim os atores envolvidos no desenrolar das transações internacionais das firmas russas que se direcionam para o mercado produtor brasileiro.

No presente trabalho também foram utilizadas as técnicas de pesquisa bibliográfica, pesquisa documental em anuários estatísticos, estabelecendo dados secundários junto à literatura especializada, englobando: documentos de órgãos especializados, jornais, literatura especializada (livros, dissertações e periódicos). O método de representação gráfica de transações foi utilizado para caracterização das atividades técnicas (bem como seu encadeamento), identificação dos atores responsáveis por tais atividades, ilustrando, assim, as diferentes configurações de transação. A metodologia foi seguida conforme especificada por Carvalho (2005).

\section{Análise e Discussão dos Dados}

A caracterização dessas transações é importante por permitir conceber possíveis caminhos encontrados pelas firmas russas para efetuar compras no mercado produtor brasileiro. $\mathrm{O}$ estudo possibilitou a visualização de quatro diferentes configurações de transação, aqui apresentadas e discutidas.

\subsection{Configuração de transação entre os atores: empresa frigorífica brasileira; trading company com habilitação para atacado russo; atacadista russo; varejista russo; e consumidor final}

Essa configuração é a que apresenta o maior número de atores envolvidos, composta por cinco atores distintos que podem ser visualizados na Figura 1. Essa Figura chama a atenção pelo alto número de atividades en- 
volvidas e um número mais alto de transações do tipo mercado, consequentemente relacionadas à finalidade de disponibilizar um bem ao seu consumidor final.

Inicialmente têm-se as 11 atividades da empresa frigorífica que comercializa o produto com a trading company com habilitação para atacado. Caso a trading company seja uma nova cliente e não conheça a fundo as atividades desempenhadas pela empresa frigorífica exportadora, a negociação baseia-se principalmente em especificação do ativo e preço. Contudo, quando a trading já é cliente da empresa frigorífica brasileira, a posição das prioridades de negociação mudam, tendo o preço como principal fator, seguido pela data de embarque do produto e somente na terceira posição entraria as especificações do produto. Vale ressaltar que nesta configuração é a trading company com habilitação para o atacado russo que desempenha o papel de importadora, sendo incumbência dela o desembaraço burocrático.

A respeito dos contratos utilizados pelas partes como referência para as atividades de comercialização, nota-se que quando uma determinada organização do tipo trading habilitada para atacado russo é uma nova cliente ou mantém uma baixa frequência de transações entre as orgamizações, o tipo de contrato utilizado não deixa margem para renegociações futuras. Caso a organização de trading company seja uma empresa com histórico positivo na condução de transações, com nível alto de frequência de transações, a estrutura contratual muitas vezes deixa margem a ajustes posteriores, sobretudo na data de embarque.

Com a posse do direito de propriedade do produto transacionado, a trading company realiza as suas atividades específicas, entre elas a contratação e a gestão do transporte de longa distância, não impedindo que tal atividade seja terceirizada, tendo a responsabilidade ainda da armazenagem (mesmo que em um curto espaço de tempo) logo após a chegada em território russo. O bem transacionado é repassado para empresas responsáveis pela intermediação no atacado da carne bovina na Rússia, que por sua vez logo após a aquisição efetua o transporte no território russo direcionando esse bem para armazéns com a finalidade de distribuição do produto (ou algumas vezes encaminhando-o diretamente sem a armazenagem).

As empresas de varejo desta configuração farão a aquisição do produto e o armazenam até o momento de dispô-lo nas gôndolas de mercados, açougues, boutiques de carne e supermercados (atores inseridos dentro do segmento de varejo). Talvez o varejo russo seja um dos segmentos com maior 
necessidade de estudo por parte de empresas brasileiras, uma vez que é esse o elo que atinge o consumidor final e que tende a ser o formador de preços para os demais elos da configuração de transação, tendo influência em uma cadeia produtiva inteira.

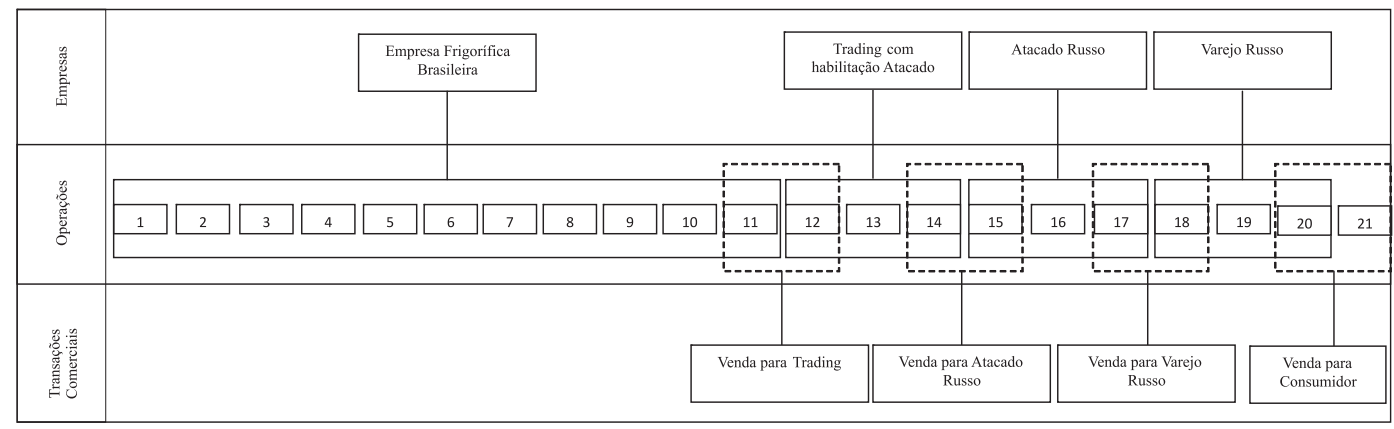

01 - Aquisição de bovinos livre de zoonoses

02 - Transporte do bovino para o local do abate

03 - Dieta hídrica

04 - Abate e primeiro corte

05 - Inspeção técnica

06 - Resfriamento de carcaça

07 - Segundo corte e desossa

08 - Processo de embalagem (rotulagem e pesagem)

09 - Resfriamento/congelamento

10 - Expedição/embarque
11 - Transporte rodoviário de longa distância até o porto no Brasil

12 - Transporte marítimo de longa distância até o porto russo

13 - Desembarque

14 - Armazenagem nas instituições de trading company

15 - Transporte para instalação do atacadista

16 - Armazenagem na instalação do atacadista russo

17 - Distribuição

18 - Descarga

19 - Armazenagem

20 - Disposição no varejo

21 - Consumo

Figura 1: Configuração de transação entre os atores empresa frigorífica/Trading Company com Habilitação para Atacado Russo/Atacadista Russo/Varejista Russo

Fonte: Resultado de pesquisa (2008)

Pode-se firmar que a principal desvantagem dessa configuração está no alto número de empresas e intermediários, quando comparada a outras configurações de atores sequenciados, o que pode resultar em elevados custos de transação, sobre tudo os ex ante. Contudo existem duas vantagens indiscutíveis nesta configuração: uma tem a ver com a alta especialização de cada categoria de organização, ou seja, cada ator se encontra desempenhando isoladamente o seu papel em uma configuração de produção e consumo. A outra vantagem diz respeito à facilitação da entrada em um dado mercado, simplesmente porque torna possível obter de pronto a colaboração de organizações atuantes neste mercado. A entrada dar-se-ia via um agente facilitador, desse modo, aprendendo e conhecendo entraves e vantagens desse mercado, criando confiança entre as partes por meio da redução de incertezas de conhecimento da estrutura, funcionamento e conjuntura de um mercado específico. 


\section{I.I Configuração de transação entre os atores: empresa frigorífica brasileira, atacadista russo, varejista russo e consumidor final}

Esta configuração apresenta internalização de operações técnicas comparadas com a anterior. Isso quer dizer que as atividades específicas do ator trading company com habilitação para o atacado russo foi absorvida por outra organização. Nese estudo de caso percebeu-se que o atacadista russo passa a ser mais proeminente, ou seja, depois de negociar produtos com a trading company com habilitação para o atacado russo, o atacadista russo tomou a iniciativa de entrar em contato com a fornecedora da respectiva trading. Isso possibilitou o fechamento de transações entre a fornecedora da trading (empresa frigorífica brasileira) e a empresa atacadista russa, conforme pode ser observado na Figura 2.

Nesta configuração de transação as atividades e as margens da trading company foram absorvidas por um parceiro comercial. Tal articulação somente foi possível por dois fatores: a) conhecimento e reconhecimento da qualidade do produto transacionado e da idoneidade entre as partes; b) iniciativa e disposição da organização atacadista russa em assumir atividades específicas de um ator, no caso a trading company com habilitação para o atacado russo.

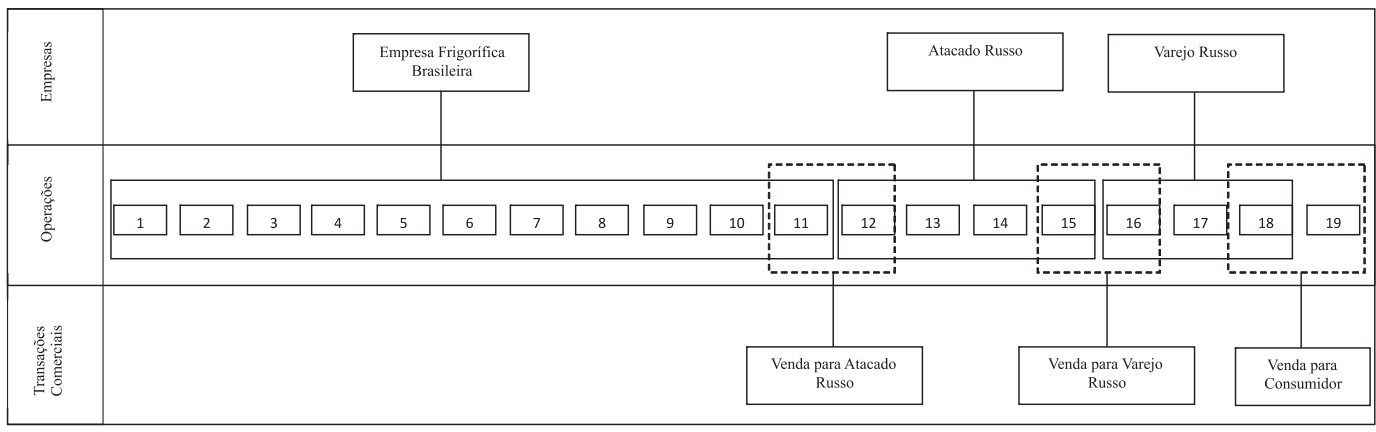

01 - Aquisição de bovinos livre de zoonoses

02 - Transporte do bovino para o local do abate

03 - Dieta hídrica

04 - Abate e primeiro corte

05 - Inspeção técnica

06 - Resfriamento de carcaça

07 - Segundo corte e desossa

08 - Processo de embalagem (rotulagem e pesagem)

09 - Resfriamento/congelamento

10 - Expedição/embarque

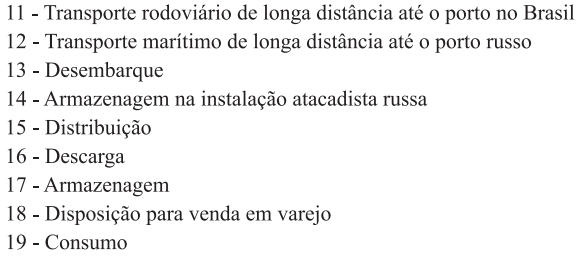

11 - Transporte rodoviário de longa distância até o porto no Brasil

12 - Transporte marítimo de longa distância até o porto russo

13 - Desembarque

14 - Armazenagem na instalação atacadista russa

15 - Distribuição

16 - Descarga

17 - Armazenagem

18 - Disposição para venda em varejo

19 - Consumo

Figura 2: Configuração de transação entre os atores empresa frigorífica/Atacadista Russo/ Varejista Russo

Fonte: Resultado de pesquisa (2008) 
Quando analisada a relação contratual entre as partes, percebe-se que há uma alta especificidade dos ativos para atender às necessidades de negócios. Contudo, não se tem uma alta frequência de transações. Desse modo, o contrato que melhor se ajustaria à transação seria o contrato neoclássico, nesse contrato se deixa margem para renegociações futuras, pois ele apresenta maior número de renegociações no tocante à data de embarque e desconto de valor.

A sequência de operações técnicas permanece igual à configuração de transação anterior, ou seja, o ator atacadista russo transporta, armazena e distribui o produto para os varejistas russos que executam as mesmas atividades de armazenamento e disposição do produto para o seu consumidor final. Isso demonstra que não acontecem mudanças nas atribuições do atacadista russo a jusante.

Essa configuração já mostra a consolidação da atuação da empresa atacadista russa no mercado produtor brasileiro, ressaltando na solidificação do network internacional, uma vez que se atingiu os níveis de confiança e de capacidade técnica necessários para implementar essa configuração. No tocante aos custos de transação, os custos ex ante são reduzidos, principalmente com relação ao custo de encontrar fornecedores e clientes e o custo para ensinar a produzir o que se necessita, contudo os custos ex post podem crescer. Vale ressaltar que esses custos ex post são agravados por questões oportunistas, contudo podem ser reduzidos na condição de consolidação de parceria.

Existe a possibilidade de ainda nesta configuração, mais especificamente no elo empresa frigorífica - atacado russo, de aparecer um novo ator, o broker, servindo como um catalisador para que a transação flua com maior rapidez. Como mencionado anteriormente, esse tipo de organização trabalha com uma rede de relacionamentos de organizações com o mesmo interesse. O broker ajuda na construção do relacionamento entre a empresa frigorífica brasileira e a organização atacadista russa.

Percebe-se que o broker não desempenha atividades específicas para com o produto: a sua função é estritamente articuladora. Tal articulação é usualmente frequente em situação de acionamento do atacado russo por clientes, gerando demanda futura. Quando a organização atacadista russa recorre a seus fornecedores habituais, mas eles não têm capacidade de atender ao aumento demandado, logo o atacadista russo recorre a um broker que buscará em sua rede de relacionamentos uma empresa frigorífica de reconhecida capacidade e que terá a função de atender à demanda gerada não colocando em risco a credibilidade do agente comercial (broker) perante a 
organização atacadista russa. Contudo, o inverso não é feito pela empresa frigorífica brasileira.

De modo geral a articulação da presente configuração com o ator broker acarreta o aumento do custo de transação relacionado à localização de clientes e fornecedores, haja vista que o agente comercial recebe seus honorários do percentual do valor transacionado entre as partes. A presença do ator broker nesta configuração é diminuta, contudo deve ser reconhecida a sua importância.

\section{I.2 Configuração de transação entre os atores: empresa frigorífica brasileira, trading company com habilitação para varejo, varejista russo e consumidor final}

Esta configuração só pode ser construída caso as partes tenham habilitação para a venda direta para o varejo russo. Como visto na configuração de transação anterior, esta também apresenta internalização de atividades específicas de um dado ator. Contudo, a integração nesta configuração é desempenhada pela trading company com habilitação para varejo, que, além de desempenhar as atividades convencionais da trading company com habilitação para o atacado (função de transporte de longa distância e trâmites burocráticos de importação de carne bovina), também armazena e distribui a produto transacionado no varejo russo, conforme pode ser visto na Figura 3.

Pode-se observar que, diferentemente das duas configurações anteriores, as empresas de varejo na Rússia são alcançadas por uma organização que não é o atacadista russo. Isso implica em uma mudança mais profunda em termos de configuração. A trading company com habilitação para o varejo russo deve apresentar uma especificidade de ativos tal que permita fazer o armazenamento de maiores volumes e principalmente na distribuição dos produtos direcionados ao varejo na Rússia, o qual permanece com as suas atividades específicas de aquisição, armazenagem e venda do produto ao consumidor final russo.

Analisando essa configuração com base nos custos de transação, notou-se que não existe presença dos custos relacionados à localização de clientes e fornecedores, tampouco custos para ensinar a produzir o que se necessita. Isso é justificado pelo alto grau de proximidade entre as partes, uma vez que um forte relacionamento comercial foi construído ao longo dos anos. Indo ao encontro da empresa frigorífica, a trading company com habilitação 
para varejo russo apresenta um grande nível de imobilização de capital devido ao grau de especificidade de ativos necessários para conseguir esse espaço no mercado russo.

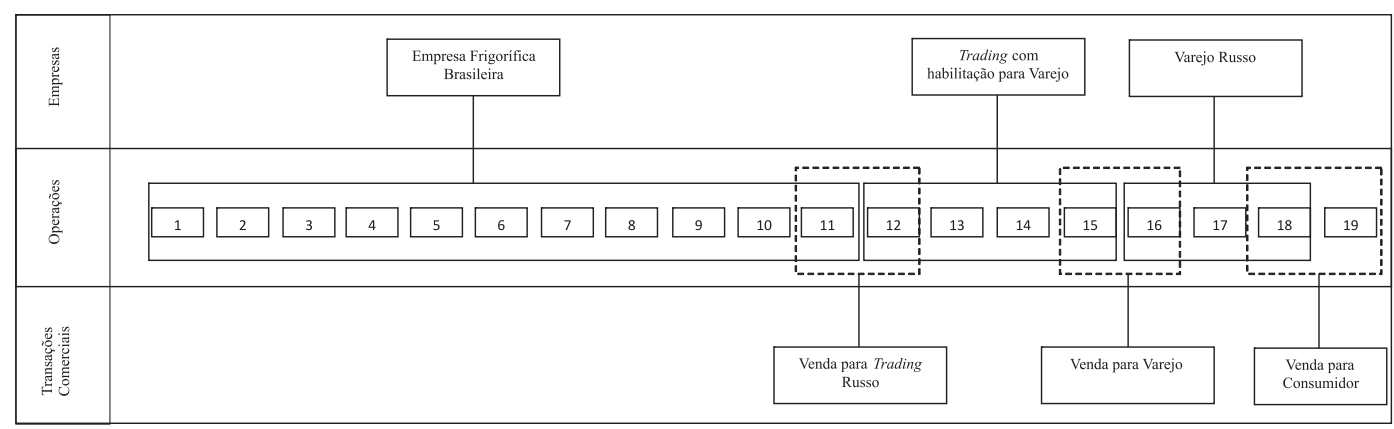

01 - Aquisição de bovinos livre de zoonoses

02 - Transporte do bovino para o local do abate

03 - Dieta hídrica

04 - Abate e primeiro corte

05 - Inspeção técnica

06 - Resfriamento de carcaça

07 - Segundo corte e desossa

08 - Processo de embalagem (rotulagem e pesagem)

09 - Resfriamento/congelamento

10 - Expedição/embarque
11 - Transporte rodoviário de longa distância até o porto no Brasil

12 - Transporte marítimo de longa distância até o porto russo

13 - Desembarque

14 - Armazenagem na instalação da trading company

15 - Distribuição

16 - Descarga

17 - Armazenagem

18 - Disposição para venda em varejo

19 - Consumo

Figura 3: Configuração de transação entre empresa frigorífica/Trading Company com Habilitação para Varejo Russo/Varejista Russo

Fonte: Resultado de pesquisa (2008)

A respeito da relação contratual encontrada, foi possível constatar que existe a possibilidade de renegociações no caso de descumprimento de compromissos firmados. Com o possível aumento da frequência das transações nesta configuração, a relação contratual pode se caracterizar como do tipo relacional (WILLIAMSON, 1985). Já na transação trading company/varejo russo a relação contratual continua sendo neoclássica. Isso está relacionado com o fato de que a trading company atua com uma carteira de possíveis clientes, muitas vezes até mesmo fora da Rússia. Nota-se então que a empresa líder nesta configuração de transação é a trading company com habilitação para o varejo na Rússia.

\section{I.3 Configuração de transação entre os atores: empresa frigorífica brasileira, varejista russo e consumidor final}

A presente configuração é a que apresenta maior nível de integração vertical e conseqüentemente o menor número de atores envolvidos. Sua con- 
formação envolve apenas os atores: empresa frigorífica tocantinense, varejista russo e consumidor final russo, com possível atuação da transação do broker. Esta configuração pode ser visualizada na Figura 04.

Apesar da aparente simplicidade, o nível de complexidade da configuração empresa frigorífica brasileira - varejo russo é acentuada, haja vista a quantidade de atividades técnicas internalizadas pela empresa de varejo russo nesta configuração quando comparada com as anteriores. Para que aconteça esta configuração, a empresa frigorífica tem necessariamente que ter a habilitação para comércio no varejo russo.

A integração vertical de atividades ocorrida deu-se por parte do varejo russo, sendo que dentre as organizações estudadas de varejo, apenas uma desempenha esta configuração, que é a empresa que atua no varejo russo de alimentos e é uma multinacional e adquiriu no ano de 2006 uma trading company que fazia a importação para mercado russo de produtos latinoamericanos, sobretudo frutas e carne bovina. Nota-se que, para a utilização desta configuração, é necessário um maior nível de especificidade de ativos, uma vez que existe a execução de atividades de alta complexidade técnica, sobretudo relacionadas à logística internacional e burocracia aduaneira russa.

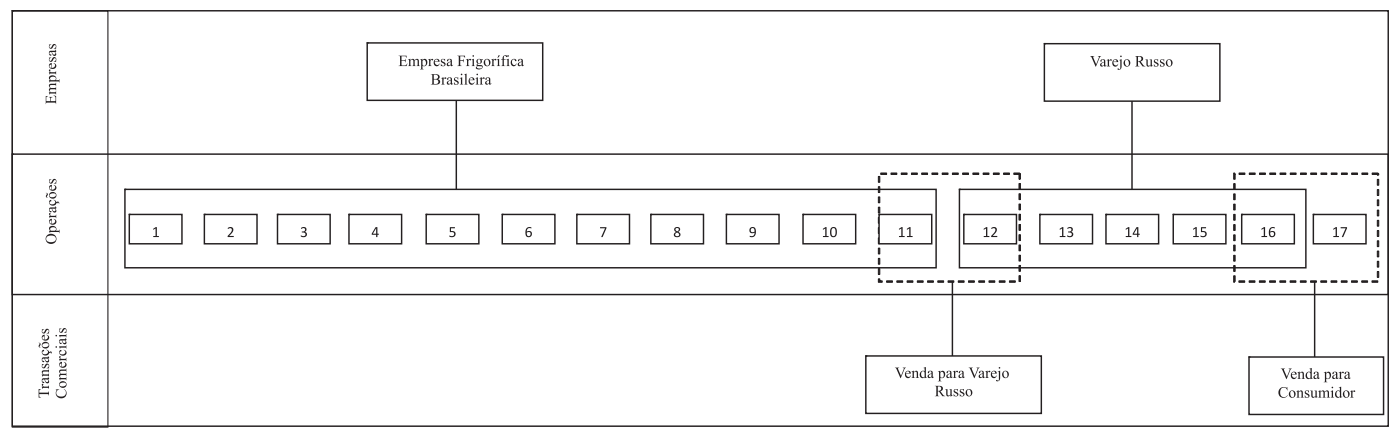

01 - Aquisição de bovinos livre de zoonoses

02 - Transporte do bovino para o local do abate

03 - Dieta hídrica

04 - Abate e primeiro corte

05 - Inspeção técnica

06 - Resfriamento de carcaça

07 - Segundo corte e desossa

08 - Processo de embalagem (rotulagem e pesagem)

09 - Resfriamento/congelamento

10 - Expedição/embarque
11 - Transporte rodoviário de longa distância até o porto no Brasil

12 - Transporte marítimo de longa distância até o porto russo

13 - Desembarque

14 - Transporte em território russo

15 - Armazenagem na instalação do varejista russo

16 - Disposição para venda em varejo

17 - Consumo

Figura 4: Configuração de transação entre empresa frigorífica/Varejista Russo Fonte: Resultado de pesquisa (2008) 
Esta configuração de transação retrata um grau mais avançado de internacionalização de negócio em relação ao mercado produtor brasileiro de carne bovina. A próxima etapa seria o investimento em instalações no Brasil, sendo caracterizado como investimento exterior não apenas na abertura de plantas de produção em território brasileiro, mas também no desdobramento de departamentos ou escritório, normalmente para facilitar o trato com fornecedores aumentando assim à proximidade entre os elos.

Apesar de um maior nível de especificidades dos ativos exigido, a relação contratual conduzida pela organização russa continua sendo a de um contrato neoclássico, deixando margem para negociações futuras apenas a data de entrega de produto no porto e a correção cambiária no dia da referida entrega. A transação é baseada principalmente na relação de prioridade de preço e data de entrega portuária. Não existe possibilidade de intermediação do broker, uma vez que esta categoria de organização reconhece que nessa configuração de transação o varejista russo lida diretamente com a empresa frigorífica brasileira, dessa maneira as partes já se conhecem e trocam informações diretamente, reduzindo assim incertezas inerentes à transação internacional.

Nota-se então que é esta configuração a que apresenta uma maior simplicidade na estrutura, isso é possível devido à eliminação de atores e atividades técnicas específicas. Deve ser observado também que a integração vertical de atividades se deu por parte da empresa varejista russa (neste caso uma rede multinacional) que consegue concretizar esta configuração por ter adquirido competências organizacionais por meio de uma aquisição e demonstrou não ter interesse em investir diretamente no Brasil por considerar um investimento não necessário para manutenção da relação de fornecimento.

\section{Conclusões}

O presente trabalho levantou seis categorias de organizações (entre organizações russas, brasileiras ou mesmo de outras nacionalidades) que estão envolvidos nas transações internacionais de carne bovina brasileira para o mercado russo. Identificaram-se quatro configurações de transações existentes e distintas, sendo que existe maior predominância da configuração da transação envolvendo a empresa frigorífica exportadora brasileira, o atacadista russo, o varejista russo e o consumidor russo (Figura 2). Nesse caso, 
observa-se uma maior responsabilidade por parte da empresa atacadista russa, o que se deve ao fato de que essa organização internalizou operações inicialmente atribuídas à trading company com habilitação para atacado russo, estreitando relacionamento com a empresa frigorífica exportadora brasileira.

A configuração envolvendo a empresa frigorífica exportadora brasileira, a trading company com habilitação para varejo russo e o varejista russo (Figura 3) foi a segunda configuração mais encontrada. Pode-se inferir que trata-se de uma situação transitória em que a trading company com habilitação para varejo russo toma a frente e é o elo entre a organização de varejo russo e a empresa frigorífica exportadora brasileira.

A terceira configuração mais frequente é a que envolve a empresa frigorífica exportadora brasileira, a trading company com habilitação para atacado russo, o atacadista russo e o varejista russo (Figura 1). Esta é a configuração que apresenta o maior número de atores envolvido nas transações internacionais. Esse grande número de intermediários tende a elevar o custo total dessa configuração. Pode-se afirmar que esse tipo de arranjo é utilizado pelas empresas russas para facilitar sua inserção em segmentos específicos do mercado produtor brasileiro de carne bovina.

Sendo a configuração menos frequente a retratada pela Figura 4 e que envolve a empresa frigorífica brasileira exportadora e a organização varejista russa, esse arranjo mostrou-se eficiente, uma vez que permite uma grande integração de atividades, eliminando assim intermediários. Esse tipo de configuração não predomina, porque exige um volume de investimentos em ativos específicos maiores que as demais, um nível mais elevado de riscos para as duas partes e um envolvimento maior nas questões técnicas, administrativas e burocráticas do comércio, sendo realizada por apenas uma organização multinacional atuante no comércio varejista russo.

Por todos os aspectos mencionados, constatou-se tendência de internacionalização de empresas russas motivadas por suprimento de produtos, impulsionadas principalmente pela liderança de custos brasileira neste setor. As configurações de transação já verticalizadas mostram a capacidade de empregar tecnologias mais avançadas, uma menor presença de intermediários e um maior nível de investimento para a gestão e funcionamento do sistema de comércio em função da internacionalização das empresas russas em direção ao mercado produtor brasileiro.

Dentro da conjuntura das transações estudadas, é importante observar que existem grandes oportunidades a serem exploradas, em que novos mo- 
delos de negócio estão sendo testados pelas empresas russas na internacionalização de seus negócios com foco no mercado produtor brasileiro de carne bovina. Esses novos modelos buscam eficiência e redução de custos, muitas vezes, excluindo parceiros que agregam pouco valor para as transações comerciais entre as partes. A confiança e o comprometimento entre as partes é um dos fatores de maior importância para configurações e posicionamento mais ativos das organizações russas em mercado brasileiro. Notou-se também a aplicabilidade da metodologia de representação gráfica para a representação da arquitetura de transações utilizada pelas organizações russas na internacionalização do seu negócio com foco no mercado produtor brasileiro.

\section{Reaching Suppliers of Bovine Meat: the presence of russian organizations in Brazil}

\section{Abstract}

This article aims to characterize Russian commercial organizations that are trading bovine meat from Brazil. It is a exploratory qualitative study. During the field work it was possible to conduct 14 interviews with Russian and Brazilian traders, from $01^{\text {st }}$ until $12^{\text {th }}$ of December/ 2008. It was found that traders developed four different types of transaction configurations. The first configuration described is the one with the highest number of organizations involved in the trading activities. It is a transaction configuration that aloud higher levels of specialization for the different trading firms, making possible for Russian wholesalers and retailers to buy from Brazilian abattoirs intermediated by international trading organizations. In the second observed configuration it was possible to perceive a more active role of the Russian wholesaler, since this category of organization was able to absorb the trading operations that where performed by an international trading company. In the third transaction configuration a trading company licensed to trade with Russian retailers is the only intermediary between Brazilian exporters and retailers. The fourth transaction configuration has a Russian retailer trading directly with a Brazilian supplier of bovine meat.

Key words: Internationalization. Transaction Costs. Beef International Trade. Russian Market. Graphical representation. 


\section{Referências}

ALMEIDA, A. (Org.). Internacionalização de empresas brasileiras. Belo Horizonte: Editora Campus/FDC, 2006.

ANDERSSON, S. Internationalization in Different Industrial Contexts, Journal of Business Venturing, New York, v. 19, p. 851-875, 2004.

BLISKA F. M. GONÇALVES, J. R. Estudos da cadeia de carne bovina no Brasil. In: CASTRO, Antonio Maria Gomes de, et al. (Ed.) Cadeias produtivas e sistemas naturais: prospecção tecnológica, Brasília, DF: Embrapa-SPI/ Embrapa-DPD, 1998. p. 157-183.

CARVALHO, J. M. Graphical representation of transaction arrangements. Revista Organizações Rurais e Agroindustriais, Lavras, v. 7, n. 2, p. 188198, 2005.

COASE, R. H. The nature of the firm. Economica, London, v. 4, p. 386-405, 1937.

CNPC - Conselho Nacional da Pecuária de Corte. Carne no mundo. 16 dez. 2008. Disponível em: <http://www.cnpc.org.br/publicacoes.php>. Acesso em: 12 fev. 2009.

DOUMA, S.; SCHREUDER, H. Economic approaches to organizations. Prentice Hall, Hemel Hempstead, 1998.

FAO - Food and Agriculture Organization of the United Nations. Faostat. 22 nov. 2008. Disponível em: <http://faostat.fao.org/default.aspx>. Acesso em: 11 jan. 2009.

FLICK, U. Uma introdução à pesquisa qualitativa. 2. ed. Porto Alegre: Bookman, 2004.

FREITAS, M. L. G. Inserção internacional de empresas de cafés industrializados do Brasil: um estudo multicaso (Mestrado em Administração) Programa de Pós-Graduação em Administração, Universidade Federal de Lavras, Lavras, 2006.

GHANATABADI, F. Internationalization of small and medium-sized enterprises in Iraq. (Doutorado em Administração de Negócios Internacionais) - Departamento Administração e Ciências Sociais, divisão de Marketing Industrial e Comércio Eletrônico. Luleå University of Technology, Luleå, Suécia, 2005. 
GODOY, A. S. Introdução à pesquisa qualitativa e suas possibilidades. Revista de Administração de Empresas. São Paulo, v. 35, n. 2. mar/abr, 1995.

MATTAR, F. N. Pesquisa de marketing: metodologia e planejamento. São Paulo, Atlas, 1996.

MAPA - Ministério da Agricultura, Pecuária e Abastecimento. Intercâmbio comercial do agronegócio: principais mercados de destino. Brasília: 2008.

MULVIHILL, D. F. Terminology in international business studies: order out of chaos. Journal of International Business Studies, p. 87-90, Spring, 1973.

NORTH, D. Institutions Institutional Change And Economic

Performance, Cambridge University Press, Cambridge, 1990.

SABADIN, C. O comércio internacional de carne bovina brasileira e a indústria frigorífica exportadora. 123 p. Dissertação (Mestrado em Agronegócio) - Programa de Pós-Graduação em Agronegócio, Consórcio entre UFMS, UNB e UFMT, Universidade Federal do Mato Grosso do Sul, Campo Grande, 2006.

THOMÉ, K. M.; CARVALHO, J. M.; LEITÃO, F. O.; RUZZON, M. A. R. Papel dos atores presentes nas exportações de carne tocantinense para o mercado russo. Revista Eletrônica de Sociedade e Desenvolvimento Rural, v. 4, Brasília, 2009.

TRIPODI, T.; FELLIN, P.; MEYER, H. Análise da pesquisa social. Petrópolis: Alves, 1975.

VAN DUREN, E. et al. Assessing the competitiviness of Canada's agrifood industry. Canadian Journal of Agricultural Economics, v. 39, Canadá, 1991.

WILLIAMSON, O. E. Markets and hierarchies: analysis and antitrust implications. New York: Free, 1975.

. The economic institutions of capitalism: firms, markets, relational contracting. New York: Free, 1985.

Transaction Cost Economics and Organization Theory. Journal of Industrial and Corporate Change, FE. p. 107-156, 1993.

WOODS, M. International business: an introduction. New York: Palagre, 2001. 